\title{
Teaching Feedback Control Theory Using An INTEgRating Design Project
}

\author{
Michel F. Couturier \\ University of New Brunswick \\ cout@unb.ca
}

\begin{abstract}
Teaching feedback control theory is challenging because it is important to cover theoretical material intended for fundamental understanding as well as material directly related to industrial practice. One approach to reach this dual objective and prevent control theory from becoming abstract to students is to assign a design project that requires integration of all main concepts taught in class. This approach has been successfully used in eight offerings of the course ChE 3601 Process Dynamics and Control in the Chemical Engineering program at the University of New Brunswick. The one-semester course is an introduction to the dynamic behavior of chemical processes and feedback control loops. The project is assigned at the beginning of the course and involves the design of a feedback control system for a realistic chemical process. The design project is divided into five milestones with deliverables due every two weeks. The final report due at the end of the course must include a description of the proposed system using a P\&I diagram, specifications for all control equipment, a dynamic model for all components of the feedback loop, settings for the tuning parameters of the PID controller, and dynamic simulations using Polymath to validate the proposed solution. The course is organized around the project in a manner similar to that used in problem-based learning. The active learning approach used in ChE 3601 provides a deeper understanding of control theory and its application.
\end{abstract}

Keywords: process control, integrating project, milestones, dynamic simulations, feedback loop.

\section{INTRODUCTION}

The first undergraduate course in automatic control systems should provide an appropriate balance of control theory and practice [1]. It is important that students gain a fundamental understanding of system dynamics and control concepts while also developing industrially relevant control skills [2]. The course should therefore emphasize dynamic modeling of physical systems, mathematical tools for obtaining dynamic responses, instrumentation and control hardware, feedback control theory, controller tuning, and control loop troubleshooting $[1,2,3]$. Achieving the right balance between theory and practice can however be difficult.

It is possible to succeed at this challenging balancing act by assigning a design project that requires integration of all major topics covered in the course. This approach has been used in eight offerings of the course ChE 3601 Process Dynamics and Control in the Chemical Engineering program at the University of New Brunswick. The course is organized around the project in a manner similar to that used in problem-based learning. The project defines the timing of the lecture material and greatly motivates the students. Although the approach presented in this paper is described in the context of our process control course, it is adaptable to other automatic control courses.

\section{COURSE STRUCTURE}

\subsection{Course Objectives}

The course ChE 3601 is a one-semester introduction to the dynamic behavior of chemical processes and feedback control loops. This 4 credit hour course comprises three 50 minute lectures and one 50 minute tutorial every week. The material covered in the course is listed in Table 1.

The order of presentation of the lecture material is set by the project as will be explained in section 2.2. After an introduction to control systems, the course covers sizing of actuators and sensors, and how to document control systems using piping and instrumentation diagrams (P\&IDs). Students are subsequently taught how to develop dynamic models for physical systems using conservation and rate equations. We then show how the dynamic models for the actuator, process, sensor and controller can be combined to simulate the dynamic behavior of feedback control loops. This discussion helps demystify mathematical models but the solution of the 
Table 1: Course syllabus

A. Process Control Systems and Hardware

- Feedback and feedforward controllers

- Control valves and sensors

- $\quad$ Piping \& Instrumentation diagrams

B. Modeling the dynamics of Chemical Processes

- Development of mathematical models for physical systems using conservation and rate equations

- Solution of ordinary differential equations using Polymath

- Linearization and deviation variables

- Transfer functions and block diagrams

- Dynamic behavior of $1^{\text {st }}, 2^{\text {nd }}$ and higher order systems

C. Analysis and Design of Feedback Control Systems

- Closed-loop dynamics

- Stability analysis of feedback systems

- Root-locus analysis

- Controller tuning

resulting set of differential equations can intimidate students.

The classical approach for solving the dynamic models is based on developing analytical solutions using Laplace transforms and transfer functions [4]. This technique is useful for demonstrating fundamental concepts and, although it is rarely directly used in industry, we continue to teach how to analyze the response and stability of linear systems in the Laplace domain. However, instead of using tedious partial fraction expansions to develop analytical solutions, we prefer to use computer simulations to obtain dynamic responses. It is now simple to solve complex nonlinear models directly in the time domain using personal computers. Computer-based simulation exercises are especially valuable in teaching controller tuning [5]. A deeper understanding of process control is nevertheless obtained when the student is not simply adjusting parameters in an interactive simulation but plays a direct role in the development of the algorithm [6]. We therefore teach how to solve systems of ordinary differential equations using the software program Polymath. Polymath requires minimal programming experience and is a user-friendly and powerful program for performing numerical calculations.

The design and analysis of feedback control systems receive considerable attention in the second half of the course, with emphasis on industry-proven methods for controller design, tuning, and trouble-shooting. The learning outcomes for the course are presented in Table 2.

\subsection{Design Project}

The project is assigned at the beginning of the first lecture and entails the design of a feedback control system for a realistic chemical process. Working in teams of two or three individuals, students must perform the design of the control system and describe their solution in a report which is due on the last day of classes. The final report must include a description of the proposed system using a P\&I diagram, specifications for all control equipment, a dynamic model for all components of the feedback loop, settings for the tuning parameters of the PID controller and results of dynamic simulations to validate the proposed solution.

The design challenge presented to the students at the beginning of the semester is significant because the process control course is generally where chemical engineering students are first exposed to the dynamic nature of chemical processes. All other courses in a standard chemical engineering curriculum typically focus on steady-state behavior [6]. The project is structured to integrate the majority of the topics covered in the course and this helps students see the industrial relevance of control theory. The course is therefore organized around the project. The timing of the lecture material and the assignments is defined by the requirements of the project. Theory is covered in class at least two weeks prior to being used for the first time in the project. Students also get to apply the theory in at least one assignment before using the theory for the first time in the project.

The projects completed to date in ChE 3601 are listed in Table 3. They were derived from case studies found in the literature and the experience of the author. The projects are examples of the five control loops commonly found in the chemical industry: flow, pressure, liquid level, product quality, and temperature.

Table 2: Learning outcomes

Students will be able to:

- Develop dynamic models for all components of a feedback loop,

- Simulate the dynamic behavior of feedback control systems using the software 'Polymath',

- Design and troubleshoot typical feedback control systems used in the chemical industry. 
Table 3: Projects completed

1) Temperature control in a steam-heated heat exchanger

2) Neutralization of an acidic wastewater stream

3) Level control in a sludge dewatering system

4) Level control in a steam-heated vaporizer

5) $\mathrm{pH}$ control in an aerobic digestion system

6) Pressure control in a steam header

7) Control system for the headbox of a paper machine

8) Temperature control to prevent a runaway reaction

\subsection{Milestones}

Guidance is provided to the students to ensure that all groups are progressing with their design at the same rate. We pace the students by setting 5 milestones that all teams must complete (Table 4). The due dates for the milestones are defined by the course schedule given to the students at the beginning of the year.

Each milestone contains a set of tasks that move the design along. The methods that should be used to complete the tasks are presented in the weekly lectures. After the material has been presented in class, students get to apply the theory in at least one assignment before using it in the project.

Every week, either an assignment or a milestone report is due. These are graded by the teaching assistant and returned to the students within a week. The feedback on the milestone reports is used by the students to improve their design and polish their report.

The final report gets assembled progressively by completing the five milestones. Each milestone report is a compilation of the sections of the final report that have been written to date. It includes a new section summarizing the design work to meet the milestone requirements along with revisions that have been made to previous sections using feedback provided by the teaching assistant. In this manner, a high quality final report gets assembled.

\subsection{Role of Teaching Assistant}

The teaching assistant is responsible for providing written feedback on the milestone reports that are submitted periodically. The teaching assistant also marks the assignments that are submitted every other week by the students.
Table 4: Typical milestones

\begin{tabular}{|c|c|c|}
\hline & Milestones & $\begin{array}{l}\text { Due } \\
\text { Date }\end{array}$ \\
\hline 1. & $\begin{array}{l}\text { Suggest a feedback control system for } \\
\text { your process. Draw a P\&I diagram. }\end{array}$ & Week 4 \\
\hline 2. & $\begin{array}{l}\text { Select control equipment from the many } \\
\text { models available commercially. } \\
\text { Specifications should include: response } \\
\text { time, type of input and output signal, } \\
\text { range of instrument. }\end{array}$ & Week 6 \\
\hline 3. & Propose a dynamic model for the process. & Week 8 \\
\hline 4. & $\begin{array}{l}\text { Develop an open-loop dynamic model } \\
\text { using Polymath. Predict the open-loop } \\
\text { response of the controlled variable to (i) a } \\
\text { step change in the main disturbance, and } \\
\text { (ii) a step change in the signal to the final } \\
\text { control element. }\end{array}$ & Week 10 \\
\hline 5. & $\begin{array}{l}\text { Propose settings for the tuning } \\
\text { parameters of the PID controller. } \\
\text { Develop a closed-loop dynamic model } \\
\text { for the process using Polymath to validate } \\
\text { the proposed solution. Submit final } \\
\text { report. }\end{array}$ & Week 12 \\
\hline
\end{tabular}

\subsection{Role of Instructor in Design Project}

Solutions used by the teaching assistant to mark the assignments are provided by the instructor. The instructor also provides general guidance to the teaching assistant on what are appropriate solutions for each milestone.

Furthermore, the overall coordination of the project is the responsibility of the course instructor. He defines the project and sets the milestones. He also explains in class the tasks to be completed in each milestone. Most importantly, he marks the final report.

\subsection{Student Evaluation}

The breakdown of the final grade of the students in ChE 3601 is provided in Table 5. The final report is worth $25 \%$ of the final mark. Although the weighting for the milestones and assignments is small, this is not indicative of the importance of these elements. It is by completing the assignments and milestones that the students really master the course material. They get to apply each concept twice; first, in an assignment and then in the project. They get feedback on both attempts and can learn from their mistakes. It is not the path followed by the students which is important but what they have learned in the end. For this reason, the final report and the exam have the largest weightings. 
Two schemes (A and B in Table 5) are used to evaluate the performance of each student and the larger of the two values is used as the final grade. Scheme A favors students who did well all term but had a bad day on the exam. Scheme B, on the other hand, favors students who struggled all term but mastered the material in the end.

Table 5: Breakdown of final grade

\begin{tabular}{|l|c|c|}
\hline & \multicolumn{2}{|c|}{ Evaluation Scheme } \\
\hline $\begin{array}{l}\text { Design project } \\
\text { (final report) }\end{array}$ & A & $\mathrm{B}$ \\
\hline $\begin{array}{l}\text { Assignments (6) } \\
\text { and first 4 } \\
\text { milestones }\end{array}$ & $10 \%$ & $25 \%$ \\
\hline $\begin{array}{l}\text { Two tests } \\
(10 \% \text { each) }\end{array}$ & $20 \%$ & \\
\hline Exam Total & $100 \%$ & $75 \%$ \\
\hline \multicolumn{1}{|c|}{ Total } & $100 \%$ \\
\hline
\end{tabular}

\subsection{Sample Design Project}

An example of the design projects completed in the course is provided in Table 6 . This project is derived from the experience of the author with the sludge dewatering system at a nearby pulp and paper mill. Control of the sludge level in the hopper of the screw press is an interesting control problem because of the transportation lag introduced in the feedback loop by the dewatering table.

Results from the final report of one group are shown in Figs. 2 to 4. The P\&ID is shown in Fig. 2 whereas openloop and closed-loop simulation results obtained with the Polymath program listed in Table 7 are presented in Figs. 3 and 4, respectively. The open-loop response is characteristic of a purely capacitive system with dead time. The dead time was simulated in Polymath by dividing the dewatering table into thirty first-order lags in series. This approximation gave good results as can be seen in Fig. 3. The closed-loop response of Fig. 4 was obtained with a PI controller having a gain of 7 and an integral time constant of 84 seconds.

The differential and explicit equations of the model are entered in Polymath in a very intuitive fashion as seen in Table 7. With very little instruction, the students can quickly use Polymath to solve sets of ordinary differential equations. Students can therefore focus their efforts on deriving the model and analyzing the results. The solution step is no longer a bottleneck in the process of getting dynamic responses via mathematical modelling.
Table 6: Level control in a sludge dewatering system

The system shown in Fig. 1 is used to dewater sludge prior to incineration. The sludge enters the system with a consistency of $1.3 \mathrm{wt} \%$ and is first pumped onto a horizontal moving belt filter where water is removed by gravity. The sludge leaves the belt filter with a consistency of about $8 \mathrm{wt} \%$ solids and falls into the hopper of a screw press. The press squeezes further water out of the sludge by pushing the sludge along a perforated cage of decreasing diameter. The sludge exits the system with a consistency of about $29 \mathrm{wt} \%$ solids.

Close control of the level in the hopper is critical for optimum operation of the screw press. This can be achieved by adjusting the flow of sludge onto the gravity table. The normal flow is $1.74 \mathrm{~m}^{3} / \mathrm{min}$.

The belt is $2.77 \mathrm{~m}$ long and $1.98 \mathrm{~m}$ wide. Its speed $\mathrm{u}$ is normally set at $75 \%$ of its maximum value of $0.133 \mathrm{~m} / \mathrm{s}$. Sludge falling into the hopper has a bulk density of 400 $\mathrm{kg} / \mathrm{m}^{3}$. The hopper has a cross-section of $0.92 \mathrm{~m} \times 0.57 \mathrm{~m}$ and is $1.2 \mathrm{~m}$ high. The funnel transition from the gravity table to the top of the hopper is $2.2 \mathrm{~m}$ high. The flowrate of sludge entering the screw press is set by the speed of the screw and is independent of the level in the hopper.

Design a system for controlling the level in the hopper. Your report must include a description of the proposed system, a piping and instrumentation diagram (P\&ID), specifications for the control equipment, and results of dynamic simulations to validate the proposed control scheme. All calculations must be clearly explained and summarized in the appendix of the report.

The final report is due on the last day of classes this semester. The attached timetable and milestones will help pace your progress and will provide opportunities for feedback. The calculations associated with each milestone must be submitted for evaluation on the indicated date. The calculations will be marked and returned quickly so that errors can be flagged and corrected early.

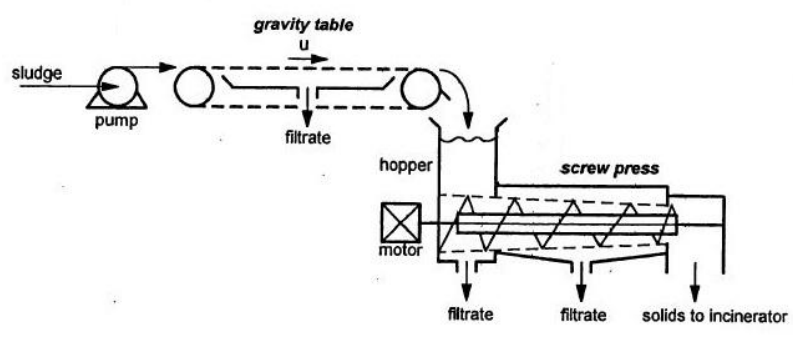

Figure 1 Sludge dewatering system 


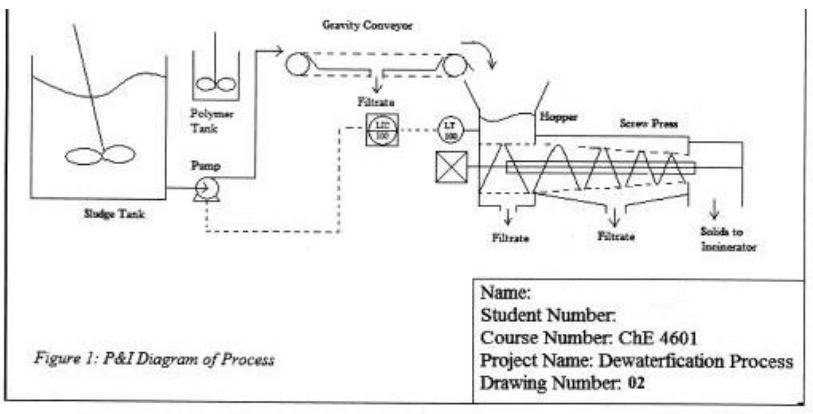

Figure 2 P\&ID for sludge dewatering system

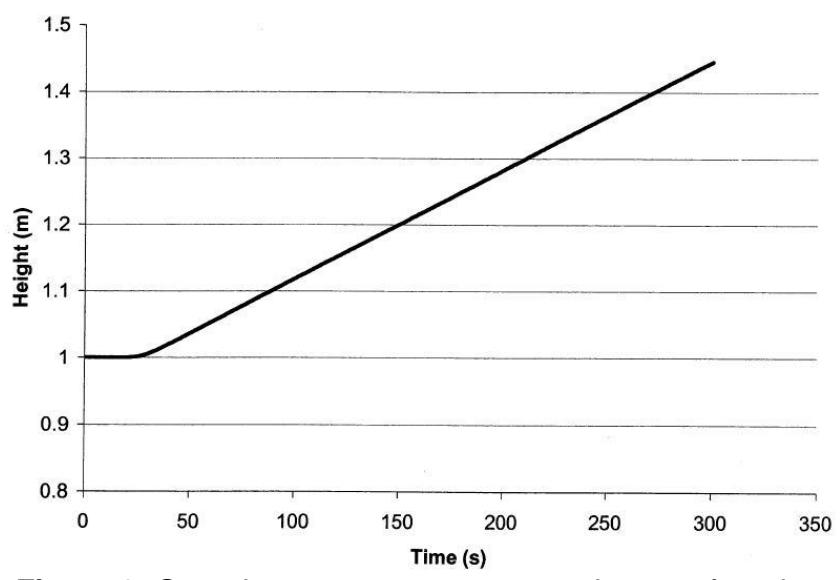

Figure 3 Open-loop response to a step change of $5 \%$ in the inlet sludge flowrate

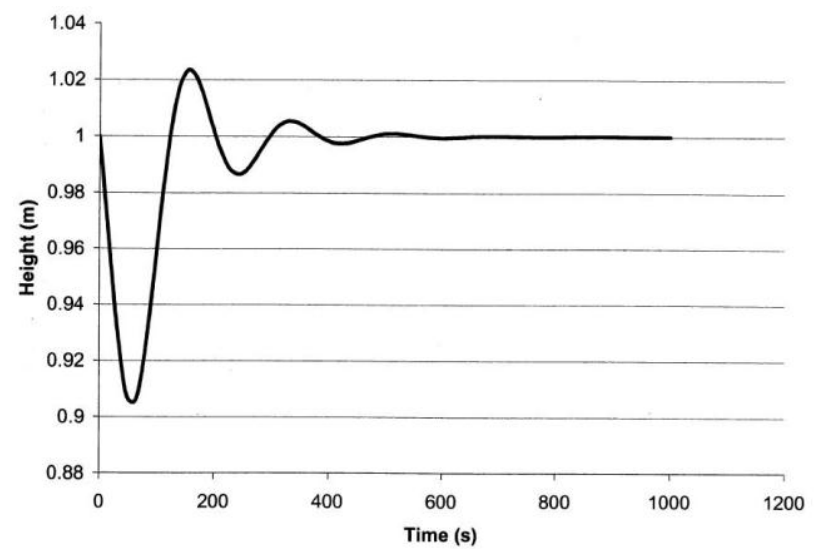

Figure 4 Closed-loop response to a step change of $10 \%$ in the screw press flowrate
Table 7: Polymath program

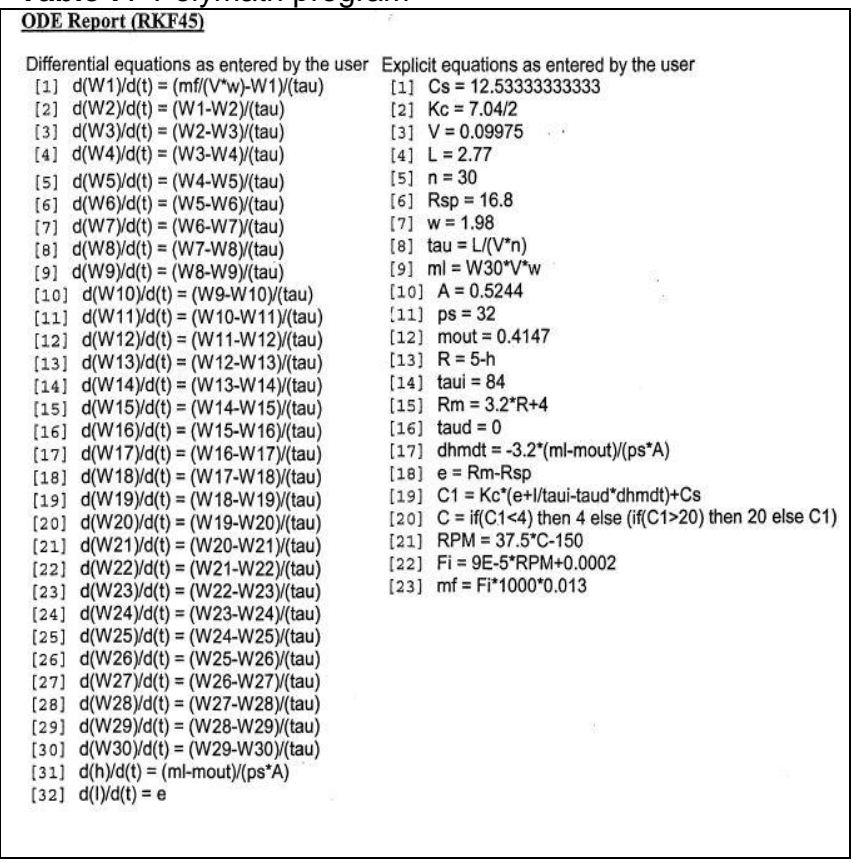

\section{RESULTS AND DISCUSSION}

The milestones are an effective management tool for pacing the students, providing feedback and producing high quality reports. The milestones compel the students to constantly work on their design project while integrating concepts presented in class. The reports submitted by each group at the end of every milestone allow the teaching assistant to periodically comment on the details of the work that has been accomplished. The feedback is used to improve the design and polish the written submission. Further gains in efficiency are obtained by asking students to format their written submissions as sections of the final report. In this manner, each submission is a new draft version of the final report. Since design is an iterative process, students must continuously revise their draft report to reflect changes in their design. Streamlining of the draft report requires some rework but produces a final report of high quality. This greatly facilitates the evaluation of the final report by the instructor.

The design of control systems is a form of scientific art guided by techniques and strategies which is best learned by practicing design on a realistic project. The milestones define the tasks that need to be completed and each group is free to decide how the tasks will be carried out. Each milestone report is worth only a small percentage of the overall course grade. The students are therefore not heavily penalized if they make mistakes while completing the milestones. It is important however that they learn from their mistakes and incorporate the feedback provided by the teaching assistant in their draft report in order to do 
well on the final report. The exam as well as the design report is used to determine whether students have reached the intended learning outcomes.

The active learning approach used in ChE 3601 provides a deeper understanding of control theory and its application. The project motivates students by helping them see how control theory can be applied in practice. The project also helps students develop industrially relevant control skills such as modelling, controller tuning and control-loop troubleshooting.

The use of a design project has however some disadvantages. More office hours must be provided to help students, especially when they are facing problems with their computer simulations. Frequency response analysis was also squeezed out of the syllabus to create class time for the presentation of material related to the project. This deletion is however not considered detrimental because the use of frequency response to analyze closed-loop systems is declining in the process industries [1]. The work associated with finding a new project every year is considered a minor drawback because the milestones replace some of the weekly assignments. Overall, the advantages of using an integrating design project to teach process dynamics and control far outweigh the disadvantages.

\section{CONCLUSIONS}

The design project introduced in the course ChE 3601 Process Dynamics and Control motivates students to learn control theory and develops industrially relevant control skills. The advantages afforded by the design project largely outweigh the drawbacks for both teacher and student.

\section{References}

[1] Dale E. Seborg, Thomas F. Edgar, Duncan A. Millichamp, and Francis J. Doyle III, Process Dynamics and Control. Hoboken, NJ: John Wiley, 2011 ( $3^{\text {rd }}$ edition), 514 pp. \{ISBN: 978-0-470-12867-1\}

[2] James B. Riggs and M. Nazmul Karim, Chemical and BioProcess Control. Lubbock, TX: Ferret Publishing, 2006 ( $3^{\text {rd }}$ edition), 578 pp. \{ISBN:0-9669601-4-9\}

[3] Carlos A. Smith and Armando B. Corripio, Principles and Practice of Automatic Process Control. Hoboken, NJ: John Wiley, 2006 ( $3^{\text {rd }}$ edition), 563 pp. \{ISBN:0-471-43190-7\}

[4] George Stephanopoulos, Chemical Process Control-An Introduction to Theory and Practice. Englewood Cliffs, NJ: Prentice-Hall, 1984, 696 pp. \{ISBN:0-13-128629-3\}

[5] F.G. Shinskey, Process Control Systems-Application, Design and Tuning. New York, NY: McGraw-Hill, $1996\left(4^{\text {th }}\right.$ edition), 439 pp. \{ISBN: 0-07-057101-5\}

[6] B. Wayne Bequette, Process Control-Modeling, Design and Simulation. Upper Saddle River, NJ: Prentice-Hall, 2003, 769 pp. \{ISBN: 0-13-353640-8\} 